\title{
INTERthesis
}

\section{GÊNERO E ESCOLA: CATEGORIAS QUE SE ENTRELAÇAM NAS HISTÓRIAS DE VIDA}

\section{Resumo:}

Beatriz Helena Viana Castro ${ }^{1}$

Cristhianny Bento Barreiro ${ }^{2}$

Este artigo apresenta o recorte de uma pesquisa a partir da qual as questões de gênero emergiram como elementos condicionantes da trajetória de escolarização, trazendo a temática acerca das origens da desigualdade entre os sexos na sociedade de classes e de que forma este panorama revela a condição de desvalorização da mulher no funcionamento dessa sociedade, ainda hoje. Essa reflexão surgiu a partir de pesquisa realizada em $2013 \mathrm{com}$ um grupo de mulheres que retornavam à escola para fazer um curso profissionalizante após alguns anos de afastamento dos estudos. Nessa pesquisa, foram ouvidas e analisadas as histórias de vida dessas mulheres com o objetivo de identificar a sua percepção acerca de seu retorno para escola e suas expectativas quanto à mesma, além de compreender os diversos aspectos que influenciaram, ao longo da vida, sua formação. Nesse estudo, identificam-se as dificuldades que elas encontram no desempenho de sua vida profissional, além de situar as mulheres no mercado de trabalho, observando não apenas a sua condição feminina, mas esta condição atrelada às nuances de etnia, raça, geração e classe social. A maternidade aparece de forma contundente nas histórias relatadas, constituindo-se numa categoria de pesquisa e reforçando a necessidade de aprofundamento dos estudos de gênero. O papel da mulher foi construído com base em uma sociedade patriarcal e, embora atualmente se fale em igualdade, esta ainda não é a realidade na maioria das relações de gênero aqui apresentadas.

Palavras-chave: Gênero. Trabalho. Maternidade. História de Vida. Educação.

\section{INTRODUÇÃO}

Este artigo apresenta parcela da discussão realizada em uma pesquisa feita com estudantes do ensino profissionalizante de um Instituto Federal de Educação, Ciência e Tecnologia. Nessa pesquisa são investigadas as razões impulsionadoras do desejo de voltar à escola por parte de mulheres acima de 30 anos que se matriculam em um curso técnico em vestuário, na modalidade subsequente, analisando suas histórias de vida.

\footnotetext{
1 Mestre em Educação e Tecnologia pelo Instituto Federal de Educação, Ciência e Tecnologia SulRio-Grandense, Pelotas, RS. Professora do Curso Tecnológico e Técnico em Vestuário no mesmo Instituto em Pelotas, RS, Brasil. E-mail: castrobh@hotmail.com

2 Doutora e Mestre em Educação pela Pontifícia Universidade Católica do Rio Grande do Sul. Docente Permanente no Programa de Pós-graduação em Educação, Mestrado Profissional em Educação e Tecnologia no Instituto Federal de Educação, Ciência e Tecnologia Sul-Rio-Grandense em Pelotas, RS, Brasil. E-mail: crisbbarreiro@gmail.com
} 
O tema pesquisado surgiu a partir da vivência em sala de aula. A preocupação em investigar as mulheres acima de 30 anos que retornam à escola, advém da experiência de sala de aula enquanto professora. Após alguns anos trabalhando com essas estudantes, percebe-se que elas chegam para estudar com muita vontade de aprender e, para isso, precisam se empenhar de forma, por vezes, muito mais intensa que as estudantes que estão em idade regular. Muitas são as barreiras que têm de vencer para concluir o curso. Problemas de diversas naturezas, tais como: dificuldades na aprendizagem, devido ao tempo de afastamento da escola, dificuldades familiares, como conciliar estudos e cuidado com os filhos, dentre outros. Ao voltar a estudar, essas mulheres acumulam mais uma tarefa em seu dia a dia, pois na grande maioria das vezes, não deixam de exercer nenhuma daquelas que já eram anteriormente suas atribuições.

Sentindo este empenho, acredita-se ser importante compreendê-las em suas expectativas, ou, pelo menos, em parte dessas, entrecruzando-as, no momento de análise, com as contribuições que a teoria pode oferecer. Esse estudo também aponta para as razões do abandono da escola e as especificidades culturais dessas mulheres, sujeitos da pesquisa.

As experiências educacionais de pessoas de todas as idades (bem como todo o tipo de materiais que contribuam para aumentar o nosso conhecimento relativo a essas experiências), tanto em contexto escolar como exteriores à escola, podem constituir objeto de estudo. A investigação qualitativa em educação assume muitas formas e é conduzida em múltiplos contextos. (BÓGDAN; BIKLEN, 1994, p.16).

A pesquisa teve como objetivo compreender as motivações de mulheres, com idade superior a 30 anos, através de suas histórias de vida, no retorno aos estudos, optando pela realização de um curso técnico profissional.

Primeiramente, é apresentada uma breve teorização acerca das questões de gênero, relacionando-as com a educação de jovens e adultos que influenciaram fortemente as discussões e análise dos resultados encontrados. Na sequência, está descrita a metodologia utilizada. Logo a seguir, a maternidade é abordada como uma das categorias resultantes das análises realizadas. Finaliza-se com algumas considerações finais acerca da investigação realizada. 


\title{
2 TEORIZANDO: AS QUESTÕES DE GÊNERO
}

A pesquisa trabalhou com uma pequena parcela de mulheres que foram precocemente excluídas do sistema educacional. A preocupação com quem está fora do sistema vem ganhando força anualmente, especialmente para com as mulheres. Percebe-se o aumento de políticas educacionais voltadas para elas, em especial à educação da mulher pertencente às camadas mais pobres da população e excluídas do sistema educacional por décadas. Programas como o PROEJA e o Mulheres Mil do Governo Federal comprovam essa preocupação.

\begin{abstract}
A exclusão é resultado de um modelo cujo objetivo é a concentração de riqueza, a fragmentação dos problemas humanos, a estigmatização dos males sociais como males inerentes aos indivíduos, incapacitando-os, dessa forma, para a conquista da cidadania. Entre os excluídos as mulheres são numerosas e as estatísticas apontam-nas como as mais atingidas pela exclusão. São numericamente as mais excluídas do emprego formal, dos lugares de decisão, dos benefícios de proteção legal, e foram historicamente colocadas à margem da esfera pública em função de uma desigualdade social que durante muito tempo foi considerada como parte de um patrimônio cultural da sociedade. (COSTA; ÁVILA, 2002, p. 12)
\end{abstract}

Nesse sentido, torna-se relevante realizar uma breve discussão sobre os fatores de retorno aos estudos a partir das relações de gênero. E, para qualquer discussão que se pretenda realizar envolvendo estas questões, é fundamental, primeiramente, conceituar gênero.

Para Eggert e Silva (2009), o conceito de gênero surgiu para se contrapor ao conceito de sexo, ou seja, gênero se refere somente aos aspectos sociais, enquanto sexo se refere à natureza, aos aspectos biológicos. Atualmente, essa conceituação está sendo questionada, já que:

[...] sexo e gênero devem ser considerados como uma unidade, pois assim como não existe uma unidade biológica desconectada do contexto social e cultural que Ihe dá suporte, também é inviável a constituição social de gênero separada de uma determinada estrutura biológica. (SILVA, 2012, p. 26).

Contudo, a autora entende que não se faz necessário abolir o uso desse termo e sim de compreender os seus limites e as relações de desigualdade entre homens e mulheres que ele pode acobertar, se utilizado inadequadamente.

Segundo Scott (1990, p. 07),

R. Inter. Interdisc. INTERthesis, Florianópolis, v.13, n.1, p. 114-133 Jan-Abr. 2016 
[...] o gênero é igualmente utilizado para designar as relações sociais entre os sexos. Seu uso rejeita explicitamente explicações biológicas como aquelas que encontram um denominador comum, para diversas formas de subordinação, no fato de que as mulheres têm as crianças e que os homens têm uma força muscular superior. O gênero torna-se, antes, uma maneira de indicar "construções sociais" - a criação inteiramente social de idéias sobre os papéis adequados aos homens e às mulheres. $O$ gênero tornou-se uma palavra particularmente útil, pois ele oferece um meio de distinguir a prática sexual dos papéis sexuais consignados às mulheres e aos homens.

O papel da mulher foi construído a partir de uma sociedade patriarcal. Eggert e Silva $(2009$, p.28) propõem uma nomenclatura mais atualizada ao termo patriarcado, de maneira que indique sua relação com o capitalismo: "patriarcalismo, dado que as classes sociais advindas desse modo de produção dão ao patriarcado qualidades específicas como a situação de subordinação feminina no mundo do trabalho e os reflexos desse processo no todo social."

As mulheres vêm conquistando um espaço significativo nas relações sociais e no mercado de trabalho, mas ainda há muito a percorrer para que sejam respeitadas e reconhecidas em nossa sociedade.

Essa é a realidade que parece persistir e a educação tem papel fundamental na desconstrução destes estereótipos relativos ao gênero feminino.

A constituição do sujeito feminino é um processo com raízes históricas que implica transformações relevantes na sociedade, uma vez que a mudança da mulher acarreta modificações nos papéis sociais que deixam de ser fixos e definidos, tornando-se abertos e indeterminados. (ZINANI, 2006, p.49).

Conforme Antunes (2002), para ingressar no mundo do trabalho os homens e as mulheres são qualificados e capacitados diferentemente, efetivando uma construção social sexuada.

O capitalismo apropriou-se dessa desigualdade reforçando a divisão sexual do trabalho. Nesse sistema econômico, o trabalhador não produz somente para consumo próprio, mas também para atender uma demanda que independe de suas necessidades. Participa do mercado não somente como consumidor, mas também como vendedor de sua força de trabalho. A força de trabalho entendida como mercadoria integra o trabalhador à sociedade de classes e a partir daí podemos analisar o papel da mulher nas sociedades competitivas.

A mulher das camadas sociais diretamente ocupadas na produção de bens e serviços nunca foi alheia ao trabalho. Em todas as épocas e lugares tem ela contribuído para a subsistência de sua família e para criar a riqueza social. Nas economias pré-capitalistas, especificamente no estágio

R. Inter. Interdisc. INTERthesis, Florianópolis, v.13, n.1, p. 114-133 Jan-Abr. 2016 
imediatamente anterior à revolução agrícola e industrial, a mulher das camadas trabalhadoras era ativa: trabalhava nos campos e nas manufaturas, nas minas e nas lojas; nos mercados e nas oficinas, tecia e fiava, fermentava a cerveja e realizava outras tarefas domésticas. Enquanto a família existiu como uma unidade de produção, as mulheres e as crianças desempenharam um papel econômico fundamental. (SAFFIOTI, 2013, p. 61-62).

$\mathrm{Na}$ França e Inglaterra do século XVII, as mulheres participavam ativamente do comércio varejista e atacadista, contudo estavam limitadas às atividades negociais. Para outras atividades sempre foi considerada inferior tendo desvalorizado seu trabalho e necessitando da tutela de um homem, muitas das vezes, seu marido.

Percebe-se então que a felicidade da mulher incluía necessariamente o casamento. Segundo Saffioti (2013, p. 63), "através dele é que se consolidava sua posição social e se garantia sua estabilidade ou prosperidade econômica."

A partir da Segunda Guerra Mundial surgiu o conceito de Estado de Bem Estar Social, em que cabe ao Estado a proteção social às pessoas cuja pobreza resultava das dificuldades de, mediante o trabalho assalariado, se sustentarem devido a acidentes de trabalho, doença desemprego e velhice. Gama (2014) questiona então de que maneira estariam contemplados os direitos sociais das mulheres, uma vez que, segundo a autora A construção dos Estados de Bem Estar Social se assenta na divisão sexual do trabalho, onde as mulheres são alocadas como mães, esposas, cuidadoras e trabalhadoras no lar, mesmo quando também estão inseridas no mercado de trabalho, enquanto os homens sustentam economicamente as famílias por meio do trabalho remunerado.

Ainda hoje, ser mulher, não é apenas ser diferente de ser homem. Implica, também, em carregar consigo o estigma da inferioridade, desvalorização do seu fazer doméstico, resultando em formas, por vezes, sutis de opressão.

Homens e mulheres adultos contam como determinados comportamentos ou modos de ser parecem ter sido "gravados" em suas histórias pessoais. Para que se efetivem essas marcas, um investimento significativo é posto em ação: família, escola, mídia, igreja, lei participam dessa produção. Todas essas instâncias realizam uma pedagogia, fazem um investimento que, freqüentemente, aparece de forma articulada, reiterando identidades e práticas hegemônicas enquanto subordina, nega ou recusa outras identidades e práticas; outras vezes, contudo, essas instâncias disponibilizam representações divergentes, alternativas, contraditórias. (LOURO, 2000 p. 17). 
As pesquisas sobre divisão sexual do trabalho tentam elucidar a relação diferenciada dos homens e das mulheres com o mercado de trabalho, com as funções mais "apropriadas" para cada gênero e o impacto dessas diferenças na qualificação das mulheres.

Os postos e as funções femininas refletem as relações sociais homensmulheres em que são atribuídas às mulheres tarefas predominantemente manuais que necessitam de "características femininas" como a capacidade de executar um trabalho simples e minucioso. As mulheres não podem ser empregadas em trabalhos pesados, perigosos, sujos e insalubres. Assim, estando as mulheres ligadas aos postos de trabalho manual e rotineiro, acabam por estarem concentradas em postos de trabalho desqualificados.

As qualificações femininas são reconhecidas como talentos naturais, fortalecendo as relações desiguais de gênero.

Logo, as funções que as mulheres exercem no mercado de trabalho, foram determinadas de acordo com as construções históricas e culturais do papel da mulher, ou seja, são funções propriamente atribuídas ao papel da mulher, como o emprego de doméstica, babá ou costureira. Trabalhos esses, que requerem apenas habilidades e qualidades denominadas como "naturais à mulher", sem a necessidade de qualificação.

Atualmente, com o aumento da inserção de mulheres no mercado de trabalho, em funções variadas, inclusive cargos de chefia, há uma mudança no modo em que elas passam a se relacionar com a qualificação. A pressão das mulheres pela conquista de igualdades relacionadas a cargos e salários, vem acompanhada pela qualificação profissional.

A Educação de Jovens e Adultos tem crescido e vem se tornando um importante espaço de superação da exclusão social daqueles que não tiveram oportunidade de acesso à escolarização na idade regular. Assim, é nessa modalidade de ensino que as mulheres estão se inserindo de modo a recuperar o tempo que estiveram afastadas, buscando superar a exclusão antes imposta a elas. Através da EJA muitas brasileiras estão iniciando ou dando continuidade à sua escolarização.

Para Bruschini (2011), a inserção das mulheres no mercado de trabalho é marcado por avanços e permanências. De um lado, com o aumento da 
escolarização, a conquista de melhores empregos, de outro lado a precarização do trabalho feminino com salários inferiores aos dos homens nas mesma funções. Segundo a autora,

[...] do ponto de vista das políticas públicas, um dos maiores desafios dos novos tempos no Brasil é promover a articulação entre família e trabalho, além de continuar implementando medidas para eliminação das desigualdades e discriminações nos ambientes de trabalho. (BRUSCHINI, 2011,p.145)

A autora ressalta ainda que, políticas sociais de transferência de renda tem contribuído para diminuição do nível de pobreza, porém programas como o Bolsa Família, do Governo Federal, reforçam os papéis tradicionais atribuídos às mulheres, visto que o benefício é concedido às "boas mães", aquelas que garantem a frequência a escola, a vacinação e o cuidado em geral dos filhos. Bruschini (2011, p.170) afirma:

É de se supor que a menor participação das mulheres beneficiárias do Bolsa Família no mercado de trabalho se deva, justamente, a sua maior responsabilidade com as condicionalidades do programa, reforçando papéis tradicionais de gênero.

HIRATA ( 2004,p.20) auxilia na compreensão do problema:

Se o papel das políticas públicas em favor da igualdade entre homens e mulheres pode ter conseqüências positivas, apenas a mudança da correlação de forças no interior da esfera dita "privada" poderá contribuir para uma melhor distribuição do trabalho invisível, do trabalho de compaixão e de dedicação, de altruísmo, de disponibilidade permanente, tornando abordável às mulheres - e não apenas virtualmente aos homens e a um punhado de "mulheres excepcionais" - um espaço próprio, um tempo "para si", e o acesso à criatividade, que é possível apenas a partir de uma afirmação de si enquanto sujeito autônomo.

\section{METODOLOGIA: OS CAMINHOS DA INVESTIGAÇÃO}

A pesquisa se construiu numa perspectiva qualitativa tratando de uma pesquisa narrativa do tipo História de Vida.

A pesquisa qualitativa trabalha em uma concepção diferenciada da pesquisa quantitativa. Segundo Neves (1996, p.01) "nas pesquisas qualitativas é freqüente que o pesquisador procure entender os fenômenos, segundo a perspectiva dos participantes da situação estudada e, a partir daí, situe sua interpretação dos fenômenos estudados."

R. Inter. Interdisc. INTERthesis, Florianópolis, v.13, n.1, p. 114-133 Jan-Abr. 2016 
Autores como Benjamin (2012), Barbier (2007), Josso (2004; 2010), entre outros, auxiliaram na composição dos instrumentos e métodos utilizados.

Para atingir os objetivos da pesquisa, o procedimento metodológico utilizado foi a história de vida. Segundo Josso (2004, p.163):

\begin{abstract}
Uma das dimensões da história de vida reside na elaboração de um autoretrato dinâmico por meio das diferentes identidades que orientam as atividades do sujeito, as suas representações e as suas projeções, tanto nos seus aspectos visíveis ou manifestos como nos invisíveis ou não explicitados.
\end{abstract}

Segundo a autora, por meio desse autorretrato mais ou menos explícito, evidenciar as posições existenciais, adotadas ao longo da vida, permite ao autor da narrativa tomar consciência da sua postura de sujeito e das ideias que, consciente ou não-conscientemente, estruturam essa postura.

Conforme Benjamin (2012, p.38),

[...] um acontecimento vivido é finito, ou pelo menos encerrado na esfera do vivido, ao passo que o acontecimento rememorado é sem limites, pois é apenas uma chave para tudo o que veio antes e depois.

A partir das narrativas, a escuta da história de vida destas alunas explicita as razões de seu retorno à escola, no contexto de uma vida, o que auxilia o objetivo de ampliar a compreensão acerca disso.

A coleta das narrativas foi realizada através de entrevistas em profundidade com cada uma das alunas, sujeitos da pesquisa, no esforço de realizar a escuta sensível. Para Barbier (2007, p.96-97), "a escuta sensível começa por não interpretar para suspender todo julgamento."

Foram pesquisadas estudantes regularmente matriculadas no Curso Técnico em Vestuário de um Instituto Federal de Educação, Ciência e Tecnologia, na modalidade subsequente. Para identificar e selecionar as estudantes que fariam parte da pesquisa realizou-se, previamente, um questionário com perguntas fechadas com o objetivo de estabelecer o critério relacionado à faixa etária. A partir dessas informações, estabeleceu-se a faixa etária das participantes que seriam pesquisadas - acima de 30 anos, considerando que as estudantes mais jovens possuem idades que não caracterizam períodos de afastamento dos estudos, condição indispensável para este trabalho. 
O público que procura esse curso é eminentemente feminino, o que chama a atenção sobre a questão do regresso à escola e o gênero.

Foram entrevistadas três alunas, que atendiam ao perfil acima citado. Conforme Josso (2010, p.92),

[...] os métodos qualitativos oferecem a possibilidade de um olhar detalhado e em profundidade sobre um número restrito de casos, de uma abordagem da singularidade e da complexidade específica em cada problemática; eles confrontam a diversidade, o único; eles exigem uma relação mais estreita e, muitas vezes, mais duradoura com os materiais ou os informantes.

As entrevistas com cada uma delas foram marcadas conforme a disponibilidade e preferência de horário e de local das mesmas. Todas as entrevistas foram filmadas e transcritas posteriormente, para só então, a partir das transcrições, começarem a serem feitas as análises. Importante ressaltar que, com todas as mulheres, foi realizada a primeira entrevista, a transcrição da mesma, reflexão acerca da história relatada, para só então ser marcada nova entrevista.

As narrativas transcritas formaram o corpus da pesquisa, sendo analisadas através de Análise Textual Discursiva, uma abordagem de análise de informações que transita entre duas formas reconhecidas de análise na pesquisa qualitativa que são: a Análise de Conteúdo e a Análise de Discurso (MORAES; GALIAZZI, 2006). Essa abordagem é constituída por três elementos principais: desconstrução dos textos, estabelecimento de relações entre os elementos unitários e compreensão do novo emergente.

Os dois primeiros elementos são obtidos pela realização de unitarização e categorização do corpus da pesquisa, através da fragmentação dos textos em unidades referentes aos fenômenos estudados, que posteriormente são relacionados entre $\mathrm{si}$, resultando em diferentes categorias. $\mathrm{O}$ último elemento consiste na compreensão deste novo cenário.

O momento da entrevista é de fundamental importância, pois já nesse instante é possível perceber diversas informações não-verbais através do comportamento das pessoas. Mesmo sem ter grande conhecimento na área, e sem a pretensão de elaborar conclusões sobre tal, foi possível perceber diferenças em cada uma das entrevistadas, através da forma como se comportaram durante a realização das entrevistas, tais como postura, tom de voz, olhar, momentos de silêncio, entre outros. A seguir, apresenta-se recorte das análises realizadas que 
evidenciou a necessidade de aprofundamento do estudo de gênero no trabalho, neste caso, a maternidade e sua relação com os processos de escolarização.

\section{RESULTADOS: A MATERNIDADE EMERGE}

Em algum momento da vida, as mulheres começam a questionar seu papel, tentando buscar melhor compreensão sobre si e sua vida. Atualmente, as mulheres questionam esse papel a elas designado e perguntam-se o que querem da vida. Como resposta, resolvem, então, retornar aos estudos.

Muitas podem ser as razões para esse retorno. Atualmente, observa-se o aumento da participação da mulher na composição da renda familiar, não raro como provedora da família. Esse cenário revela a necessidade das mulheres na busca pela qualificação, porém muitas das vezes, elas não dispõem de tempo suficiente para aprofundar seus estudos em um curso superior, e buscam essa qualificação através da formação profissional de nível médio.

Várias são as dificuldades a serem enfrentadas nesse retorno, a começar pela jornada dupla ou, às vezes, tripla de trabalho a que estarão submetidas, uma vez que, continuarão responsáveis pelos cuidados do lar e dos filhos e enfrentarão ainda, em alguns casos, a falta de apoio familiar para concluir seus estudos.

Esse retorno pode representar, para além da qualificação profissional, uma elevação da autoestima através da valorização dos seus conhecimentos por parte de seus familiares. $O$ fato de possuir uma profissão contribuiria muito nesse sentido. Além disso, a escola é um local de convívio e muitas dessas mulheres têm grande limitação em sua vida social, devido à sobrecarga de atividades a que estão submetidas diariamente. O simples convívio com outras pessoas, por si só, já representa uma oportunidade de mudança e de aprendizado.

A partir do exposto, apresenta-se um cruzamento entre as discussões de gênero já realizadas anteriormente e o entendimento a respeito do papel da mulher na contemporaneidade, a partir da compreensão presente nas falas das mulheres pesquisadas.

Percebe-se no relato de todas a força da maternidade como definidora de suas escolhas. Nas três falas aparece fortemente que muitas das decisões tomadas por essas mulheres, no decorrer de suas vidas, foram consequência de seu papel de 
mãe. O exercício da maternidade surge como limitador ou impulsionador do seu processo de escolarização.

Conforme fala de uma das pesquisadas, o seu retorno aos estudos se deu no exercício da maternidade. Ela voltou a estudar quando sua filha, com 10 anos de idade, começou a participar do Grupo Tholl ${ }^{3}$ e treinava todos os dias no Colégio Municipal Pelotense. Ela a acompanhava e como precisava ficar esperando resolveu aproveitar esse tempo em que achava estar ociosa, dentro de uma escola para, segundo ela:

Um dia eu me sentindo, vamos dizer assim, ociosa dentro daquele tempo que eu permanecia lá, eu me questionei, mas porquê? Se eu tô aqui, se eu venho todos os dias para cá, por que não ocupar esse tempo de uma outra maneira que seria estudando?

Então, ainda que de maneira indireta, o seu retorno aos estudos foi impulsionado pelo exercício da maternidade, corroborando a necessidade de realizar nesse estudo a discussão de gênero. Foi nesse retorno que ela concluiu o ensino médio e, conforme sua fala não parou mais de estudar.

Outra entrevistada relata que enfrenta dificuldades para se manter estudando pois se sente, e é, responsável por sua filha, conforme pode ser percebido no trecho:

[...] as vezes tinha trabalho, alguma coisa pra fazer, eu tinha que faltar pra levar ela ao médico, isso ai também me afetou, mas também eu pensava, eu tenho que ir porque eu sou a mãe, mas ainda bem que algumas professoras entenderam, outras não deram chance de fazer o trabalho de novo.

A terceira entrevistada conta que ficou grávida com 17 anos de idade. Ficou grávida de sua primeira filha e quando estava com 21 anos teve o segundo filho. Até então, continuava morando com sua mãe. Quando nasceu o segundo filho foi morar em Rio Grande com o pai da criança, onde morou por dois anos e depois retornou

\footnotetext{
${ }^{3}$ A OPTC - Oficina Permanente de Técnicas Circenses foi criada, de fato, em junho de 1987 e de direito em abril de 2004, em Pelotas/RS. O Grupo Tholl foi agregado como nome fantasia desde 2006, data em que a montagem de circo-teatro "Tholl, Imagem e Sonho" conquistou a crítica e arrebatou plateias pelo Brasil. A OPTC foi "acidentalmente" fundada em 1987 quando João Bachilli, liderando um grupo de amigos (todos atletas de ginástica olímpica competitiva e apaixonados pela arte circense), resolveu aliar todo aprendizado acrobático ao teatro e à dança. Surgiu então a ideia de realizar uma "oficina" objetivando selecionar mais integrantes e criar um grupo circense, um circo sem lona e picadeiro, mas atuando em teatros e na rua. Disponível em: http://grupotholl.com/content/index.php?secao=historico. Acesso em 19 out 2013.
}

R. Inter. Interdisc. INTERthesis, Florianópolis, v.13, n.1, p. 114-133 Jan-Abr. 2016 
para casa da mãe, com os filhos. Conta que quando sua filha era pequena tentou voltar a estudar, mas não conseguiu, pois teve que trabalhar.

Quando retornou de Rio Grande voltou a estudar a noite em uma escola particular, pois afirma que "se eu pagar não vou parar", foi quando concluiu o ensino médio. Nesse momento de sua vida, cuidava de dois filhos, trabalhava de dia e estudava a noite.

Por conta disso, cabe aqui o aprofundamento do debate sobre o papel da mulher na atualidade e de que forma ele vem sendo exercido, ou não, por elas.

A construção social sobre os sexos determina papéis diferentes para os homens e para as mulheres. São criadas representações sobre o que é ser homem e o que é ser mulher; as pessoas não nascem homem ou mulher, mas são formados (construídos) homens e mulheres. A sociedade busca, intencionalmente, através de múltiplas estratégias e táticas, "fixar" uma identidade masculina ou feminina "normal" e duradoura. (LOURO, 2000, p. 17). Historicamente, por muitos anos, as únicas funções das mulheres eram casar, cuidar do marido e dos inúmeros filhos que gerassem.

As identidades de gênero e sexuais são, portanto, compostas e definidas por relações sociais, elas são moldadas pelas redes de poder de uma sociedade. (LOURO, 2000, p. 06).

Bitencourt (2013, p. 103) afirma que,

A dicotomia público e privado na construção dos papéis de gênero, que determinou que as mulheres possuíam uma natureza mais adequável ao espaço doméstico, nutriu historicamente uma representação materna pautada no "ser cuidadora" dos filhos. Portanto, totalmente responsável por eles. O atributo de "cuidadora" ainda permeia o simbólico vinculado ao feminino, ou seja, as mulheres ainda incorporam este atributo ligado ao cuidado da casa, dos filhos e muitas vezes, dos pais na velhice.

A representação de que a mãe é a principal responsável pelo cuidado do filho é o que parece ainda vigorar na sociedade contemporânea. A obra da pesquisadora mexicana Lagarde y de Los Rios (2005) explicita uma categoria que sintetiza o papel social exercido por todas as mulheres, a categoria de madresposa.

Desde el nacimiento, y antes incluso, los seres humanos de sexo femenino son esperados y son recebidos, historicamente, com um destino. Las niñas nacem madres y lo serán hasta la muerte, de manera independiente de la realización material, de la progenitura. (LAGARDE Y DE LOS RIOS, 2005, p.398).

R. Inter. Interdisc. INTERthesis, Florianópolis, v.13, n.1, p. 114-133 Jan-Abr. 2016 
É possível notar a força que esse papel exerce, mesmo que muitas vezes de forma inconsciente, na vida das mulheres. Pode-se perceber isso no relato de uma das mulheres pesquisadas, ao se referir a sua gravidez:

[...] foi planejada. Foi planejada por mim. Era o momento biológico, aquela coisa que a gente diz, relógio biológico, eu tinha 26 anos e sempre cuidei dos filhos dos outros, porque quando eu trabalhava nas escolinhas era os filhos dos outros que estavam nas minhas mãos. [...] então é aquele vínculo que tu cria e eu sou uma mulher que pra mim a maternidade era uma coisa meio que de predestinação, sempre quis ser mãe.

A responsabilidade pelo cuidado dos filhos por parte das mulheres aparece de forma explícita também nas falas das outras duas pesquisadas ao relatarem que após as suas separações dos pais das crianças, tomaram para si, de forma irrestrita, o compromisso de criar, manter e educar seus filhos e assim fizeram e fazem, cada uma dentro de suas possibilidades e entendimentos do que a maternidade representa.

NEVES (1996, p. 53) aponta que:

[...] apesar da intensidade do crescimento da força de trabalho feminina, as pesquisas chamam atenção para a permanência de determinados traços culturais e sociais que impedem uma participação mais efetiva da mulher no mercado de trabalho. Com certeza a responsabilidade com a família, a execução de tarefas domésticas, que ainda permanecem como responsabilidade da maioria das mulheres, e a maternidade, com a exigência de cuidados com os filhos pequenos, condicionam a participação feminina no mercado de trabalho.

Analisando o exposto até aqui, podemos inferir que "tanto as ciências humanas e sociais, como as teorias evolucionistas, baseadas na biologia, cada uma a seu tempo e de seu modo, tem ressignificado suas construções, de forma a buscar entender o universo feminino na sua completude." (SILVA, 2012, p.160).

Importante associar a esse debate outra dimensão, que é a classe em que vivem e de que são originárias essas mulheres. É preciso que se atente que essas mulheres são pessoas provenientes de classes de baixa renda. Não se pode deixar de explicitar essa dimensão, pois a realidade vivida por essas mulheres difere em muito das mulheres de classes mais favorecidas financeiramente. Suas vidas são permeadas pela necessidade de suprir, muitas das vezes, a insuficiência de condições mínimas de conforto e bem estar. Necessidades como a que revela uma pesquisada em seu relato:

R. Inter. Interdisc. INTERthesis, Florianópolis, v.13, n.1, p. 114-133 Jan-Abr. 2016 
[...] trabalhei em camelô, trabalhei em hotel, de camareira, e a grande, a pior de todas as coisas, sempre insatisfeita. Eu ia pro hotel, trabalhei 2 anos de camareira, trabalhei lá porque eu precisava, precisava muito, a casa onde eu morava, que eu moro, só que tá diferente, o meu quarto e da minha filha tava num estado assim precário, aí trabalhei no hotel pra juntar dinheiro, pra construir um quarto pra mim, fora outras coisa que eu consegui fazer, mas consegui construir meu quarto.

Bitencourt em pesquisa realizada com doutorandas verificou que:

[...] a figura da "dona de casa" representa o lado negativo, que caracterizou historicamente o feminino. O atributo de "cuidadora" alocado ao feminino é compreendido como uma evidência altamente negativa para estas mulheres construírem suas identidades de gênero. Esse repúdio pela "dona de casa", esse "medo" de tornar-se uma delas carrega a influência do discurso feminista que tratou a esfera privada, ou seja, o lugar da reprodução, a partir de um simbólico atrelado à dominação. Do mesmo modo, a maternidade seria uma situação que deixaria a mulher com menos liberdade para explorar a sua criatividade e capacidade intelectiva. (BITENCOURT, 2013, p. 101)

A partir do enunciado, é razoável constatar a diferença de entendimento sobre a maternidade entre as mulheres pesquisadas, que possuem como grau de instrução o nível médio e as mulheres pesquisadas pelo autor, com grau de instrução mais elevado, pós-graduadas.

Esse comportamento explicitado na fala das doutorandas pode ser resultado de anos de luta dos movimentos feministas. A realidade dessas mulheres é caracterizada pela dicotomia do público e privado. A construção de uma profissão no mundo público é atravessada pela categoria de gênero, e as escolhas entre vida profissional e vida familiar, na visão dessas mulheres, são impossíveis de serem conciliadas pois não visualizam mudanças na esfera do privado.

Em relação à maternidade, essas mulheres se utilizam de um expediente que é privilégio de pessoas socialmente favorecidas, que é o recurso da maternidade tardia. Desfrutam dessa opção apoiando-se na oferta da tecnologia reprodutiva ou ainda, entregando o cuidado de seus filhos a outros, muitas vezes, as mulheres socialmente desfavorecidas, como as pesquisadas no trabalho aqui citado.

Atualmente, a mulher vive uma realidade com aspectos paradoxais, de um lado preserva e valoriza papéis e valores tradicionalmente atribuídos a ela, como o de esposa, mãe, cuidadora dos filhos e organizadora do espaço doméstico, por outro lado, assume o papel de controle sobre suas escolhas e busca alternativas que proporcionem sua inserção ou permanência no mercado de trabalho.

R. Inter. Interdisc. INTERthesis, Florianópolis, v.13, n.1, p. 114-133 Jan-Abr. 2016 
A partir do exposto acima, pode-se concluir que as mulheres que participaram dessa pesquisa pretendem, através do retorno aos estudos, se libertar desse papel imposto a elas pelas circunstâncias da vida, e assumir um novo papel que se evidencia para a mulher na contemporaneidade.

\section{CONSIDERAÇÕES: PALAVRAS FINAIS}

A abertura teórica e metodológica, marca desta pesquisa, permitiu a emergência de conhecimentos que ultrapassaram o espaço escolar. Essa postura é expressa por Barbier (2007, p.65) e apresentada como abertura do que se pretende afirmar ao término deste trabalho:

Os sujeitos não são mais ratos de laboratório, mas pessoas que decidiram compreender ou lutar e não aceitam ser privados das análises ligadas às informações transmitidas aos pesquisadores e diretamente saídas de suas tragédias cotidianas.

O autor explicita nesse trecho a importância de pesquisar, não só para o pesquisador, mas também para os pesquisados.

A partir do objetivo geral da pesquisa, alguns temas apareceram, antes mesmo da definição da metodologia. As discussões sobre as especificidades de gênero e educação de jovens e adultos se tornaram fundamentais para os delineamentos seguintes.

Araújo e Scalon (2005), ao analisarem os resultados apresentados em pesquisa realizada em 195 municípios de 24 estados brasileiros com enfoque nos vários aspectos das relações de gênero no âmbito da família, concluem que as ações que buscam a igualdade nas relações de gênero não são distribuídas aleatoriamente. Para as autoras, a participação no mercado de trabalho e níveis mais elevados de qualificação são pontos positivos para a conquista de um ideário mais igualitário, afirmam ainda que a educação formal é um veículo importante nessa busca ainda incipiente, uma vez que observam ainda a existência de valores baseados em uma cultura patriarcal reproduzindo os papéis tradicionais de homens e mulheres.

A metodologia utilizada - história de vida - foi escolhida a partir do entendimento que, dessa maneira, conseguiria envolver e comprometer as alunas 
com a pesquisa. Ao relatar sua história, a pessoa se sente ouvida e valorizada, o que, talvez, poucas vezes tenha acontecido na vida dessas mulheres.

Segundo Koning (2006, p. 62):

$\mathrm{Na}$ reflexão sobre si próprio em que o sujeito, numa dinâmica de compreensão, objectiva sua forma de falar do mundo em que está inserido, o sujeito, num distanciar crítico da sua forma de pensar as coisas, consciência mais crítica e mudar atitudes e formas de agir. É isto também que permite ao "eu" desta história descrever sua experiência subjectiva, torná-la num objecto sobre o qual é possível reflectir para, a seguir, confrontá-la com outros textos (outra idéias e teorias). Neste confronto toma ainda mais distância da sua própria experiência, o que vai aumentar a sua disponibilidade para a mudança e a sua capacidade de formular novas pistas de acção e intervenção.

Ao proporcionar a estas mulheres a oportunidade de contar suas histórias foi possível despertar nelas, reflexões que talvez não tenham realizado anteriormente. O resultado dessas reflexões é elemento que escapa ao tempo e propósito do trabalho de pesquisa. É preciso tempo para que estas mulheres possam, ou não, qualificar suas ações, a partir de novas compreensões.

Após ouvir e refletir sobre as histórias relatadas pelas três mulheres, começou-se a análise das mesmas. Dessa análise, resultou a categoria maternidade. Essa categoria emergiu, a partir da Análise Textual Discursiva empreendida como método, procurando nas histórias as razões impulsionadoras do retorno aos estudos, de forma a alcançar o objetivo proposto.

A maternidade aparece de forma contundente nas histórias relatadas. É possível afirmar que o cuidado dos filhos tem sido historicamente uma especificidade das mulheres. A discussão necessária é de que forma esta construção social tem afetado a vida das mulheres naturalizando uma certa representação de maternidade que serve ao capitalismo e ao patriarcado.

Badinter (1985, p.13) em Um Amor Conquistado - O Mito do Amor Materno, ajuda a pensar,

O amor materno foi por tanto tempo concebido em termos de instinto que acreditamos facilmente que tal comportamento seja parte da natureza da mulher, seja qual for o tempo ou o meio que a cercam. Aos nossos olhos, toda mulher, ao se tornar mãe, encontra em si mesma todas as respostas à sua nova condição. Como se uma atividade pré-formada, automática e necessária esperasse apenas a ocasião de se exercer. Sendo a procriação natural, imaginamos que ao fenômeno biológico e fisiológico da gravidez deve corresponder determinada atitude maternal.

R. Inter. Interdisc. INTERthesis, Florianópolis, v.13, n.1, p. 114-133 Jan-Abr. 2016 
Aliando a escola a essa reflexão, propõem-se debater como os professores e professoras que trabalham com grupos de mulheres devem considerar essa especificidade na construção de uma docência que auxilie essas mulheres a entender que podem e devem lutar pelas suas escolhas, quaisquer que sejam elas. Acredita-se que através de discussões com essas mulheres seja possível despertar nelas a vontade de questionar o cumprimento de seu papel de mulher/mãe/profissional.

Ao pensar em metodologias, entende-se que é importante se ter em mente que estas estudantes - adultas - possuem dificuldades e facilidades diferentes daquelas que se encontram realizando cursos com idade considerada regular. Como consequência disso não é produtivo que se trabalhe com as adultas da mesma maneira que trabalhamos com as meninas. É preciso que se possa pensar em novas maneiras de desenvolver as atividades de sala de aula para melhor atendêlas.

Ao finalizar essa pesquisa, acredita-se que ainda há muito a ser estudado sobre os temas aqui relacionados. Sem a pretensão de encerrar o debate sobre de que forma os professores podem contribuir para que as mulheres, ou os estudantes em geral, sendo adultos, possam concretizar seu desejo de estudar, aponta-se a necessidade de aprofundamento dessas questões. 


\title{
GENDER AND SCHOOL: CATEGORIES INTERTWINED IN LIFE STORIES
}

\begin{abstract}
:
In this essay, we present part of a research from which gender issues have emerged as conditioning elements of schooling trajectory, enabling the theme about the origins of inequality between genders in class society and how this panorama reveals woman's devaluated condition operating society today. This reflection has emerged by a research conducted in 2013 with a group of women returning to school to join a course after a few years away from studies. In this research, the life stories of these women were heard and analyzed in order to identify their perception and expectations about their return to school, as well as to understand the various aspects that influenced, throughout their lives, their education development. In this study, we identify the difficulties they've encountered in the performance of their professional lives, and in addition we situate women in the labor market by noticing not only their feminine condition, but also conditions linked to ethnic nuances, race, age and social class. Maternity appears forcefully in the reported stories, turning it into a research category and reinforcing the need for further development of gender studies. The role of women was built upon a patriarchal society and although currently the equality concept is widespread, it is still not a reality in most gender relations.
\end{abstract}

Keyword: Gender. Life stories. Work. Maternity. Education.

\section{GÉNERO Y ESCUELA: CATEGORÍAS QUE SE ENTRELAZAN EN LAS HISTORIAS DE VIDA}

\section{Resumen:}

Este articulo presentada el recorte de una investigación a partir de la cual emergieron las cuestiones de género como elementos condicionantes de la trayectoria de escolarización, trayendo la temática acerca de los orígenes de la desigualdad entre los sexos en la sociedad de clases y de qué forma este panorama revela la condición de desvalorización de la mujer en el funcionamiento de esa sociedad, aún hoy. Esa reflexión surgió a partir de investigación realizada en 2013 con un grupo de mujeres que regresaban a la escuela para hacer un curso profesional después de algunos años alejadas de los estudios. En esta investigación, fueron oídas y analizadas las historias de vida de esas mujeres con el objetivo de identificar su percepción acerca de su retorno a la escuela y sus expectativas em relación a la misma, además de comprender los diversos aspectos que influenciaron su formación a lo largo de la vida. En este estudio, se identifican las dificultades que ellas encuentran en el desempeño de su vida profesional, además de situar las mujeres en el mercado de trabajo, observando no apenas su condición femenina, mas esta condición conectada a las variantes de etnia, raza, generación y clase social. La maternidad aparece de forma contundente en las historias relatadas, constituyéndose en una categoría de investigación y reforzando la necesidad de profundización de los estudios de género. El papel de la mujer fue construido con base en una sociedad patriarcal y, aunque hoy en día se hable en igualdad, esta aún no es la realidad en la mayoría de las relaciones de género.

Palabras clave: Género. Historia de Vida. Trabajo. Maternidad. Educación. 


\section{REFERÊNCIAS}

ANTUNES, Ricardo. Os sentidos do trabalho: Ensaio sobre a afirmação e a negação do trabalho. 6. ed. São Paulo: Editora Bomtempo, 2002.

ARAÚJO, Clara; SCALON, Celi. Gênero, família e trabalho no Brasil. Rio de Janeiro, Editora FGV, 2005.

BADINTER, Elisabeth. Um Amor conquistado: o mito do amor materno. Rio de Janeiro: Nova Fronteira, 1985.

BARBIER, René. A pesquisa-ação. Brasília: Liber Livro Editora, 2007.

BENJAMIN, Walter. Magia e técnica, arte e política: ensaios sobre literatura e história da cultura. 8. ed. São Paulo: Brasiliense, 2012.

BITENCOURT, Silvana Maria. Maternidade e carreira: reflexões de acadêmicas na fase do doutorado. Jundiaí: Paco Editorial, 2013.

BÓGDAN, Robert; BIKLEN, Sari. Investigação qualitativa em Educação: fundamentos, métodos e técnicas. Porto: Porto Editora, 1994.

BRUSCHINI, Maria Cristina. O progresso das mulheres no Brasil. Rio de Janeiro: CEPIA; Brasília: ONU Mulheres, 2011.

COSTA, Ana Alice; ÁVILA, Maria Betânia. Um debate crítico a partir do feminismo: reestruturação produtiva, reprodução e gênero. São Paulo: CUT, 2002.

DARWIN, Charles. A origem das espécies por meio da seleção natural ou a preservação das raças favorecidas na luta pela vida. São Paulo: Editora Escala, 2009.

GAMA, Andrea de Sousa. Trabalho, família e gênero. São Paulo: Cortez, 2014.

EGGERT, Edla; SILVA, Márcia Alves da. A tecelagem como metáfora das pedagogias docentes. Pelotas: Editora da Universidade Federal de Pelotas, 2009. 
JOSSO, Marie-Christine. Experiências de Vida e Formação. São Paulo: Cortez, 2004.

JOSSO, Marie-Christine. Caminhar para si. Porto Alegre: EDIPUCRS, 2010.

KONING, Marijke Maria Helena. Lugares Emergentes do Sujeito-Mulher. Viagem com Paulo Freire e Maria de Lourdes Pintasilgo. Porto: Edições Afrontamento, 2006.

LAGARDE Y DE LOS RIOS, Marcela. Los cautiveros de las mujeres: madresposas, monjas, putas, presas y locas. México: UNAM, 2005.

LOURO, Guacira Lopes (org.). O corpo educado: Pedagogias da Sexualidade. Belo Horizonte: Autêntica, 2000.

MORAES, Roque; GALIAZZI, Maria do Carmo. Análise textual discursiva: processo reconstrutivo de múltiplas faces. Revista Ciência \& Educação, v.12, n.1, p. 117128, 1996. Disponível em: http://www.scielo.br/pdf/ciedu/v12n1/08.pdf Acesso em: 23 jan 2013.

NEVES, José Luis. Pesquisa Qualitativa - características, usos e possibilidades. Caderno de Pesquisas em Administração, São Paulo, v.1, n. 3, p. 103-113, 1996.

SAFFIOTI, Heleieth I. B. A mulher na sociedade de classes. 3. ed. São Paulo: Expressão Popular, 2013.

SCOTT, Joan. Gênero: uma categoria útil de análise histórica. Educação e Realidade, Porto Alegre, v.16, n.2, p.5-22, jul./dez.1990.

SILVA, Márcia Alves. Trabalho de mulher?!: alinhavando, bordando e costurando trajetórias de artesãs. Pelotas: Editora da Universidade Federal de Pelotas, 2012.

ZINANI, Cecil Jeanine Albert. Literatura e Gênero: a construção da identidade feminina. Caxias do Sul: Educs, 2006.

\section{Artigo}

Recebido em 01 de Setembro de 2015

Aceito em 26 de Fevereiro de 2016

R. Inter. Interdisc. INTERthesis, Florianópolis, v.13, n.1, p. 114-133 Jan-Abr. 2016 